\title{
Changes of the Mathematics 2017 National High School Exam in Vietnam: Compatibility with the current Calculus Curriculum?
}

\author{
Le Thai Bao Thien Trung, ${ }^{1, *}$ Tang Minh Dung ${ }^{1}$, Nguyen Thi Nga ${ }^{1}$, Vuong Vinh Phat ${ }^{2}$ \\ ${ }^{1}$ Department of Mathematics and Informatics, Ho Chi Minh City University of Education, Vietnam \\ ${ }^{2}$ Faculty of Education, An Giang University -Viet Nam National University, Ho Chi Minh City, Vietnam
}

Received August 6, 2020; Revised November 17, 2020; Accepted November 29, 2020

\section{Cite This Paper in the following Citation Styles}

(a): [1] Le Thai Bao Thien Trung, Tang Minh Dung, Nguyen Thi Nga, Vuong Vinh Phat, "Changes of the Mathematics 2017 National High School Exam in Vietnam: Compatibility with the current Calculus Curriculum?," Universal Journal of Educational Research, Vol. 8, No. 12A, pp. 7316 - 7323, 2020. DOI: 10.13189/ujer.2020.082514.

(b): Le Thai Bao Thien Trung, Tang Minh Dung, Nguyen Thi Nga, Vuong Vinh Phat (2020). Changes of the Mathematics 2017 National High School Exam in Vietnam: Compatibility with the current Calculus Curriculum? Universal Journal of Educational Research, 8(12A), 7316 - 7323. DOI: 10.13189/ujer.2020.082514.

Copyright (02020 by authors, all rights reserved. The authors agree that this article remains permanently open access under the terms of the Creative Commons Attribution License 4.0 International License.

\begin{abstract}
In 2017, the change of exam format from the constructed-response test to the multiple-choice test of the Mathematics National High School Exam in Vietnam has many conflicting opinions. In this context, the article examines the compatibility between the Calculus content (accounting for the largest proportion) in this exam and the current curriculum requirement. In the Anthropological Theory of Didactics framework, we model the math content in the exam and the teaching by mathematical praxeologies. This study uses two methods: (1) comparative analysis of mathematical praxeology in the exam and current textbooks; (2) experiment with a modified version of the types of math tasks identified in the test. The first method identifies new types of tasks in the exam but does not appear in textbooks; the second shows that answering multiple-choice questions does not guarantee that students fully understand the Calculus concepts. On the other hand, the multiple-choice test may not be enough to assess the students' competence in the new mathematics curriculum in 2018.
\end{abstract}

Keywords Vietnamese Mathematics National High School Exam, Curriculum, Calculus Teaching, Multiple-choice Question

\section{Introduction}

The educational curriculum is a structural compound of many ingredients, among which Goals, Content, Materials, Forms of teaching, Student activities, Assessment are the core components [13]. These components are closely connected themselves to ensure the success of the educational curriculum. However, the practice of education in some countries can operate differently from the theory of curriculum development. Under the influence of an electoral education in history, exams greatly influence a person's career in Vietnam. This social concept still has a strong presence in Vietnamese society today, despite the modern perspective about recruiting and training human resources in foreign countries.

In some cases, the exam questions cause significant changes in teaching and learning. For example, research $[15,16]$ has shown that the question about integrals in the test 2017 National High School Exam in Vietnam is different from the frequently asked questions in the textbook, classroom shifts, and this distinction has forced teachers to change the questions given to students in the class. Whether this impact is within the curriculum's regulations and orientations, the exam is part of it. 


\subsection{Context of Vietnamese Education}

To visualize the relationship between the exams and the teaching in the context of education in Vietnam, the article will introduce the evolution of mathematics curriculums and the evolution of college and university entrance exams in period first 20 years of the 21st century.

\subsubsection{The evolution of mathematics curriculums}

The school system of Viet Nam is now divided into three parts:

- Elementary school: 6 years old to 11 years old students, grade 1 to 5

- Lower secondary school: 11 years old to 15 years old students, grade 6 to 9

- Upper secondary school: 15 years old to 18 years old students, grade 10 to 12

After the country's unification in 1975, Vietnam underwent three great reforms in the mathematics curriculums. These reforms started with elementary school and ended in high school, respectively, in 1990, 1998, and 2006. For these changes, the author of the reforms was also the author of textbooks. [1]

To prepare for the reform in 2006, the mathematics curriculum was initially designed in two parts, respectively, for Natural Sciences and Social Sciences. However, this plan failed after commencing in the 2003-2004 school year because few students chose the Social Science orientation. This curriculum has led to the publication of two sets of textbooks since 2006, including standard and advanced textbooks. Most teachers have used standard textbooks.

On December $26^{\text {th }}$, 2018, the Ministry of Education and Training of Vietnam issued a new school curriculum [12] (after many drafts). This new curriculum will be implemented from the school year 2020-2021. For the first time, the new curriculum emphasizes developing learners' competency and quality and putting it parallel (but more critical) in equipping math knowledge for students. Some reasons for this reform are:

- Globalization shows the need to equip students with new skills and abilities to adapt.

- Reports suggest that the current curriculum is so theoretical and does not equip students with the necessary qualifications to live and work in a new era. Many wealthy families give their children to study in developed countries. There is a lack of confidence in the Vietnamese education system.

\subsubsection{The evolution of college and university entrance} exams

In Vietnam, the training time in colleges is three years long, and the training time in universities ranges from 4 to 6 years. Vietnamese society attaches great importance to highly educated people. Therefore, going to a good university is the primary goal of most students, and university entrance exams are more complicated than college entrance exams and greatly influence the content and teaching methods in high school.

From 1990 to 2001, the university and college exams took place after the high school graduation exam (around the end of May every year). Two university exams were organized between July 1 and July 20, and one college exam in August. Candidates could register for three rounds to increase their chances to enter university or college. Universities created their tests themselves, relying on the material provided by the Ministry of Education and Training. Mathematical problems in the test were complicated and went beyond the content of textbooks. Content in the official textbook was only used for the high school graduation exam. This situation led many students to move to big cities to prepare for the exam they wished to pass.

However, between 2002 to 2014, universities were no longer allowed to create their tests. The Ministry of Education and Training took responsibility for the university and college entrance exams, taking place one month after the high school graduation exam. During this period, a common exam took place on the same day for all universities, and the content of this exam gradually became more in line with the content of high school curriculums and textbooks.

Since 2015, the high school graduation exam and university entrance exam have been merged into one single exam called the National High School Exam. The Ministry of Education and Training organizes this exam and its content. Its results are used both for high school graduation and admission to universities. The content is only based on standard high school textbooks. This assessment manner leads teaching to only focus on the content of standard high school textbooks and on types of tasks that appear in the 180 minutes test.

From 2017, the Vietnamese Ministry of Education and Training has changed the form of the mathematics exam, from constructed-response test to multiple-choice test, and according to the statement of Ministry, the format and role of the exam will essentially remain until 2024.

Noticeably, in the math exams, the Ministry of Education and Training always publishes a list of calculators allowed in the examination room, and this list is updated each year according to the appearance of new calculators' versions. In other words, the element of technology is continuously being strengthened to provide the best support for candidates when taking the exam.

\subsection{Problems Stated Since the National Highschool Exam in 2017}

In the current curriculum in 2006, society witnessed two changes in the high school maths exams. Compared to the first change in 2015, which was related to the exam's role, the second one in 2017 related to the test's 
format and received lots of mixed reviews [5]. Some people supported the multiple-choice test format because of its strong points: more positive in the grading process (by machine) and assessing more aspects in the curriculum [4]. However, many others disagreed with this format $[14,17]$ due to the suspicion toward evaluating mathematical thinking and the weakness of university students' mathematical ability enrolled from this time. In this context, this article concerns whether the content is compatible with the using curriculum.

\section{Theoretical Framework}

\subsection{Anthropological Theory of Didactics}

In the anthropological theory of didactics (ATD), Chevallard used the concept of didactic transposition to explain the process of transforming knowledge from a community of mathematicians into content that can be taught in a community like a school and what students perceive [2]. (Figure 1)

In order to analyze how knowledge is taught, ATD uses a praxeological model. It is defined as a quadruple [T, $\tau, \theta$, $\Theta$ ] where all human activities exist in performing a task $t$ of a particular type T; this type of tasks $\mathrm{T}$ is resolved by a technique $\tau$; the technique $\tau$ is justified by a technology $\theta$ which at the same time allows it to be thought, or even to produce it, and which in turn is justifiable by a theory $\Theta$.

We consider the quadruple $[\mathrm{T}, \tau, \theta, \Theta]$ as a list of two blocks: $[\mathrm{T}, \tau]$ and $[\theta, \Theta]$. The first block can be considered as knowledge in action. The second one is theory knowledge. This model allows analyzing the coherence between a type of task in the textbook exercise or the assessment test and its techniques with the definitions and theorems defined in the curriculum.

In this research, ATD allows us to model mathematical content in the college entrance examination and teaching. From there, they are allowed to be compared with each other.

\section{Methodology}

In this research, we implement two methods in the connection. Firstly, doing a comparative analysis between mathematical praxeology associated with new types of tasks in the exam and mathematical praxeology in the current textbooks to clarify the reasons for appearing those differences, then evaluating their compatibility with goals and requirements of the current system. [7]. Secondly, surveying with questions having the same type of tasks, which have been adjusted, (1) to affirm mistakes that students might make, but the questions have not been clarified yet, and (2) to raise some adjustments of tasks which should be introduced to meet goals and requirements of the curriculum better.

Our study is limited to the 2017 National High School Exam and only has the Calculus content (which takes up the most questions). This time marks the first time that the exam changed from a constructed-response test to a multiple-choice test. The test contains fifty multiple-choice questions (The proportion of Calculus questions is relatively high, about 26\%) in 90 minutes. The 2017 National High School Exam took place from $22^{\text {nd }}$ to $26^{\text {th }}$ June 2017, but earlier, the Ministry of Education and Training has published three illustrations of the exam:

- The first illustrated test was published on October 5, 2016, under the name: "The mathematics illustrated test for the 2017 National High School Exam”. [8]

- The second was published on January 20, 2016, under the name: "the mock mathematics test for the 2017 National High School Exam”. [9]

- The third illustrated exam was published on May 1, 2017, under the name: "the mathematics reference test for the 2017 National High School Exam”. [10]

Thus, the four exam papers above are materials that we will analyze.

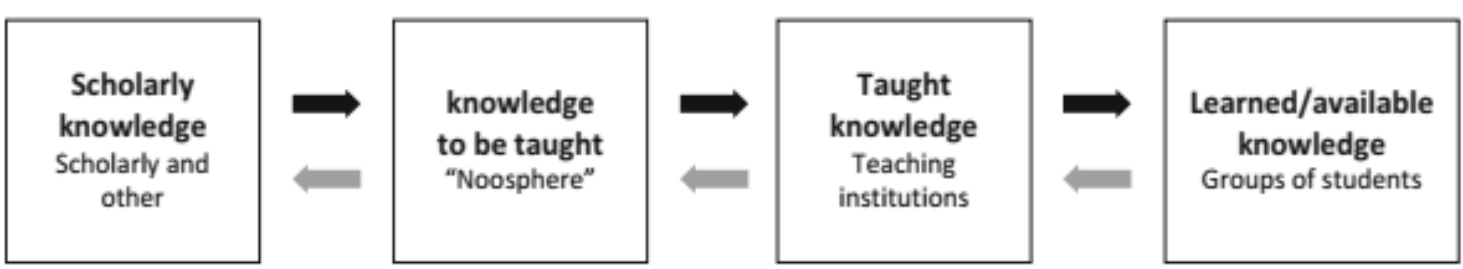

Figure 1. Diagram of the process of didactic transposition [3, p.171] 


\section{Result 1: Comparison between the Multiple-Choice Questions in the exam and the Requirements/ Contents in the Curriculum/ Textbook}

\subsection{A Note of Teaching Calculus in Math Curriculum}

Limited to Calculus teaching, the current curriculum's goal is "teaching and learning mathematics in secondary school aim to help students attain basic knowledge about function, limit, derivative, integral and their application" (math curriculum 2006, p.5). However, previous university entrance exams until the 2015-2016 school year and current textbooks almost exclusively represent functions using algebraic formulas. It means that all math problems related to function in university entrance exams (and almost all math problems related to functions in textbooks) start giving a formula. The graphical representation is a result of a process of study of function formula. The surveys [19] show that when we give students a graphical representation, they will try to find a respective formula. The types of tasks related to the concepts of limit, derivative, and integral work only emphasize algebraic transformation techniques and rarely mention the meaning of concepts. For example, in the surveys of [18], 73\% (out of 131 students learned the concept of limit of function) write a guide of calculating the limit to explain the meaning of the limit:

$$
\lim _{x \rightarrow 1} \frac{x^{2}-1}{x-1}=2
$$

\subsection{Multiple-choice Questions and New Types of Tasks}

"Study the variation and draw the graph of a function given by an algebraic expression" is a typical type of task in the Calculus teaching of Vietnamese high school. This type of task always appears in the first question of a high school graduation exam and university entrance exams until the 2015-2016 school year. The technique which is used for solving this task is long and complicated. Therefore, with this type of task, the Ministry of Education and Training limits, teaching only three types of functions in high school. This limitation leads to the phenomenon that students memorize the graph shapes for each type of function and do not need to understand the functions' properties to draw their graphs.

The typical type of task described did not appear in the illustrated and official tests. Instead of this, new types of tasks (especially where the way of function representation is changed) were introduced. We modelled two types of tasks from new questions, one appearing on the illustrated test and the other on the official exam of the 2017 National High School Exam.

\subsubsection{New type of tasks 1}

Consider question 14 of the code 102 test of the 2017 National High School Exam (there are a total of 24 tests coded from 101 to 124):

"The curve below is the graph of a function $y=a x^{4}+b x^{2}+c y=a x^{4}+b x^{2}+c$ where $a, b, c$ are real numbers.

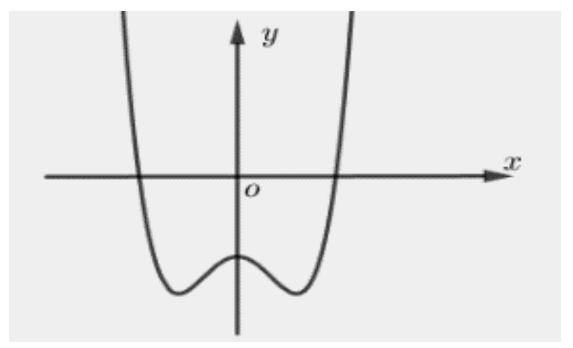

Which statement is true?

A. Equation y' $=0$ has three real distinct roots.

B. Equation $y^{\prime}=0$ has two real distinct roots.

C. Equation y' $=0$ has no real root.

D. Equation y' = 0 has only one real root.” [11, p.2]

If we ignore four results in $\mathrm{A}, \mathrm{B}, \mathrm{C}$, and $\mathrm{D}$, then we will have a new task absent in the textbook. In order to study this task, we can consider that this task belongs to the type of tasks:

T-graph: "Determine the number of roots of the equation $\mathrm{y}^{\prime}=0$ from a given curve which is the graph of a polynomial function $y=a_{n} x^{n}+a_{n-1} x^{n-1}+\ldots a_{1} x+a_{0}$."

Of course, we can generalize this task with another type that can be more/or less general than $\mathrm{T}$.

Which technique can students (who learn with the current textbooks) mobilize to solve T-graph?

Analyzing the current textbooks for all types of tasks that mention the relationship between the derivative of a function, and the graph allows us to list the techniques that may appear.

\begin{tabular}{|l|l|l|}
\hline \multicolumn{1}{|c|}{ Technique 1 $\left(\tau_{1}\right)$} & \multicolumn{1}{|c|}{ Technique 2 $\left(\tau_{2}\right)$} & \multicolumn{1}{|c|}{ Technique $3\left(\tau_{3}\right)$} \\
\hline $\begin{array}{l}\text { Count the number } \\
\text { of local maximum } \\
\text { and minimum. }\end{array}$ & $\begin{array}{l}\text { - Try to find out a } \\
\text { formula of function. } \\
\text { - Find } y \text { '. } \\
\text { - Solve equation } \\
y '=0 .\end{array}$ & $\begin{array}{l}\text { Count the points } \\
\text { at which the } \\
\text { tangent at that } \\
\text { point is parallel to } \\
O x .\end{array}$ \\
\hline
\end{tabular}

Which one of these three techniques would appear the most?

Technique 3 is based on the geometric meaning of the derivative. However, this meaning only presents in the theory part of textbooks when the textbook presents the definition of the derivative. There is no exercise about this meaning.

Vietnamese students may think firstly about technique 2 because they have exclusively worked with the algebraic formula of function through secondary school. However, in this case, that is so complex and needs much time. Therefore, we can guess that technique 1 would appear the most. 
Now we consider the block $\left[\mathrm{T}, \tau_{1}\right]$ with the question: Why students will use technique 1 ? or which is the block theory $[\theta, \Theta]$ to explain $\tau_{1}$ ?

Fermat's theorem in the current textbooks: "Suppose function $f$ has local maximum or minimum at $x_{0}$. If $f^{\prime}\left(x_{o}\right)$ exist, then $f^{\prime}\left(x_{o}\right)=0$. ." [6, p.11]

This theorem is mobilized for some types of tasks in the textbook in a way that makes students think that the function $\mathrm{f}$ has a local maximum or minimum at $\mathrm{x}_{0}$ if or only if $f^{\prime}\left(x_{0}\right)=0$.

\subsubsection{New type of tasks 2}

Consider question 4 in the illustrated test for the 2017 National High School Exam:

"Function $y=f(x)$ is continuous on R and have the following variation table:

\begin{tabular}{|c|c|c|c|c|c|}
\hline$x$ & $-\infty$ & 0 & 1 & & $+\infty$ \\
\hline$y^{\prime}$ & + & - & 0 & + & \\
\hline
\end{tabular}

Which of the following statements is true?

A. The function has exactly one local maximum or minimum.

B. The function has a minimum value equal to 1 .

C. The function has an absolute maximum value equal to 0 and an absolute minimum value equal to -1 .

D. Function attains the local maximum at $\mathrm{x}=0$ and attains the local minimum at $\mathrm{x}=1$. ." $[8, \mathrm{p} .1]$

We can consider that this task belongs to the type of tasks:

T-variation table: "Find the local maximum or minimum of the function (if they exist) from a given variation table of a function which defined and continuous on R."

Which technique do students (who learn with the current textbook) mobilize to solve the T-variation table?

They can read from the shape of the chart in the variation table. Nevertheless, students will encounter the question: Can a function get a local maximum or minimum at a point where it is not differentiable? More specifically, whether the function reaches a local maximum at $\mathrm{x}=0$ in this case.

Meanwhile, all the functions in the current textbooks' exercises have derivatives at the local maximum or minimum. Therefore, we can predict that many students will disagree that the function can have a local maximum (or minimum) at the no-derivative point.

\subsection{Difficulty in Dealing with Questions Not Found in Current Textbooks}

Our survey results also show that students' difficulty in new types of tasks is not found in current textbooks. Besides, when assessed using multiple-choice questions, some types of tasks are disabled by the calculator. For example, students can use handle calculators to solve the tasks that appear in the first illustration test for the 2017 National High School Exam:

"Question 12. Solve the equation $\log _{4}(x-1)=$ 3. $\log _{4}(\mathrm{x}-1)=3$
A. $x=63$
B. $x=65$
C. $x=80$
D. $x=82 ”[8$, p.2]

"Question 25. Calculate the integral $I=\int_{0}^{\pi} \cos ^{3} x \cdot \sin x d x$
A. $I=-\frac{\pi^{4}}{4}$
B. $I=-\pi^{4}$
C. $\mathrm{I}=0$
D. $I=-\frac{\pi}{4},[8, \mathrm{p} .4]$

The above tasks (if we ignore four results in A, B, C, D) belong to the main types of tasks in the relevant subjects such as logarithmic equations, definite integral in the current textbooks.

The wave of abuse calculator promotes the transformation of the tasks in textbooks. As a result, there are so many new types of questions that teachers and students feel embarrassed by this sudden change. Here are some questions in the reference test for the 2017 National High School Exam:

"Question 45. How many $m$ integers are there in the closed interval [-2017; 2017] so that the equation

$\log (m x)=2 \log (x+1)$ has only one solution?
A. 2017
B. 4014
C. 2018
D. $4015 ”[10, p .5]$

“Question 27. Given that $\int_{0}^{1} \frac{d x}{e^{x}+1}=a+b \ln \frac{1+e}{2}$ with a, b rational numbers. Calculate $S=a^{3}+b^{3} . S=a^{3}+b^{3}$
A. $S=2$
B. $S=-2$
C. $\mathrm{S}=0$
D. $S=1 ”[10, p .4]$

With the special cases analyzed, and the pressure to go to university, students going to extra classes have not decreased.

\section{Design the Surveys}

We conducted two surveys on the $12^{\text {th }}$-grade students who prepare for the 2018 National High School Exam. In the surveys, students were asked to answer individually in 10 minutes. The first survey is related to the new type of tasks T-graph: "Determine the number of roots of the equation $\mathrm{y}^{\prime}=0$ from a given curve which is the graph of a polynomial function $y=a_{n} x^{n}+a_{n-1} x^{n-1}+\ldots a_{1} x+a_{0}$, assigned to 110 students in Ho Chi Minh City. The second is related to the new type of tasks T- variation table: "Find the local maximum or minimum of the function (if they exist) from a given variation table of a function which is 
defined and continuous on R," assigned to 134 students in Binh Duong province. We describe the details of the two surveys below.

\subsection{Survey 1}

From the T-graph, we specialize in the following question:

The curve $\left(C^{\prime}\right)$ in the figure below is a graph of the function $y=a x^{5}+b x^{3}+c$. Find the number of solutions of $y^{\prime}=0$.

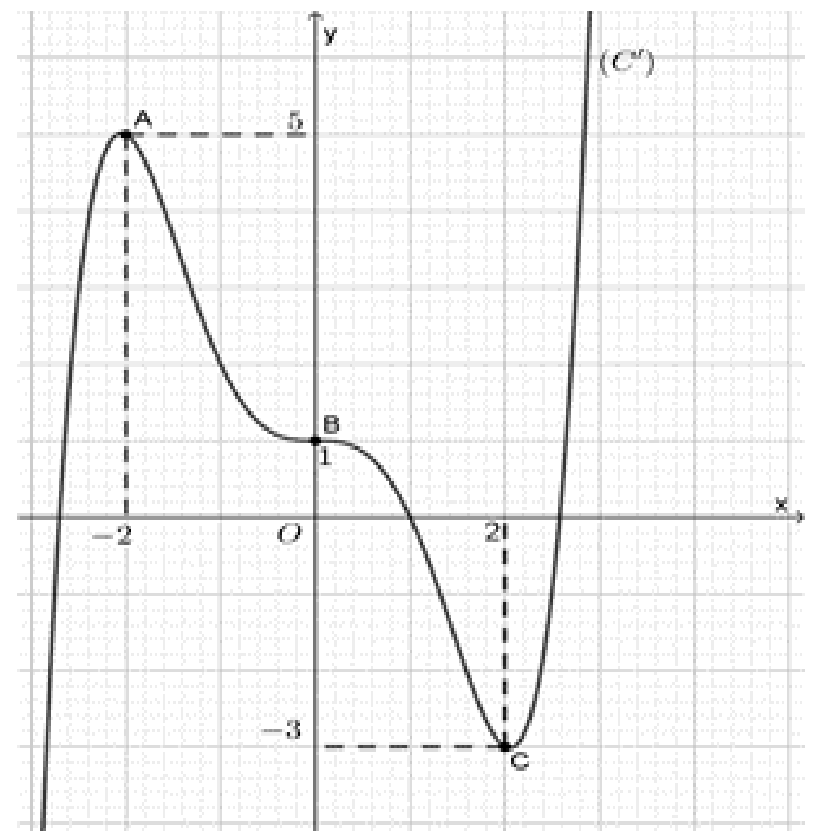

This function has two extremes (in the Mathematics textbook used in Vietnam, we often use the term extreme instead of local maximum or minimum). However, equation $y^{\prime}=0$ has three solutions because it has three stationary points.

If students use technique 1 because of the current textbook's influence, they will incorrectly answer that $\mathrm{y}^{\prime}=$ 0 has only two solutions.

\subsection{Survey 2}

From the T-variation table, we specialize in the following question:

Let the function $y=f(x)$ be defined and continuous on $R$ and have the following variation table:

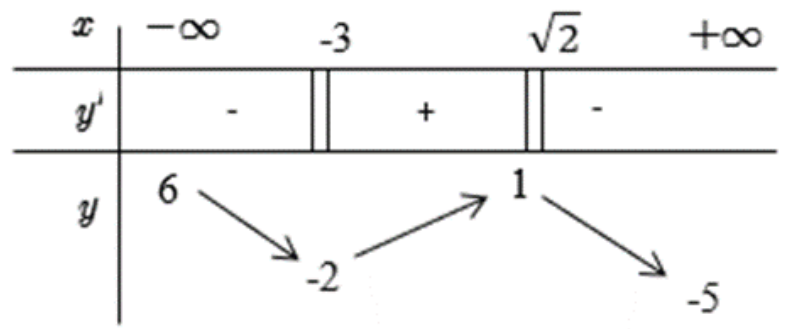

a) Does this function have a local minimum at $x=-3$ ? Explain the answer.

b) Does this function have a local maximum at $x=\sqrt{2}$ ? Explain the answer.

c) Explain the numbers 6 and -5 in the chart of the variation table.

By the extreme definition, the function reaches the extreme at the point in question. However, since none of the textbook exercises mentioned such cases, we anticipate many students to disregard the fact that the function reaches its maximum at the points where the derivative does not exist.

\section{Result 2: Doubt about Multiple-choice Questions}

After collecting data, we classify students' responses and compare them with predictions in the analyzes of section 4.2.

In survey $1,88 \%$ of students count the local maximum and minimum and answer by 2 .

In survey 2, 30\% of students said that the function has no local maximum or minimum because the derivative at -3 and $\sqrt{2}$ does not exist. $40 \%$ of students tested accepted that the limits of -5 and 6 are absolute minimum value and absolute maximum value of the function.

Student mistakes in our surveys support the suspicion of the multiple-choice questions in mathematics test of the National High School Exam, an important exam because the University in Vietnam is based and successful students' performance in this test to gain admission. Students may answer correctly on multiple-choice questions but based on a misconception.

\section{Discussion: Challenges of Assessing the Students' Competency in the New Mathematics Curriculum}

The analytical and experimental results above have shown that although the assessment plays a vital role in implementing an educational curriculum, the contents that appear in the National High School Exam, at least in Calculus, show the disconnection between assessment and requirements of the current curriculum. Based on Vietnam's educational practice, many teachers try to repair this unevenness by changing the teaching content, adding and raising the standard curriculum on the testing situation. (see the case of integral in [16]).

Some cases related to testing and assessment can be named, such as in 2015, there was an event that created a dispute among Vietnamese educators. The case showed that although Vietnam was the country with the lowest average income among the OECD countries participating 
in Pisa's assessment, Vietnamese students' performances were ranked $8^{\text {th }}$ out of 72 participating countries. This result raised many questions, including: What is the significance of Pisa's evaluation in the case of Vietnam? Are there any other factors affecting this evaluation result? (Some people suspect that these students are prepared in advance. This suspicion is due to the phenomenon of learning in advance is very popular in Vietnamese society). In case this was an accurate result, it can lead to many more intricate problems: Although the current curriculum requirements are not mentioned directly in the Pisa test's requirement, Vietnamese students still complete the test well. Therefore, why do we need a reform (the new curriculum 2018) when having a good Pisa result? One possible explanation is that students have already learned beyond the standard national curriculum to adapt all the examinations. The actual learning contents had already been very different from the syllabus's original intention because of many strong effects from the extra examinations that do not follow the requirement of the current Mathematics curriculum.

In the context of the curriculum issued in 2018, developing mathematical competencies is a major goal. However, the way to assess mathematical competency is still unclear. In particular, the multiple-choice test cannot fully assess the students' competence. The process of ensuring Mathematics teaching based on the goals of competency is a challenge.

\section{Conclusions}

In Vietnam, university entrance exams affect actual teaching contents at the school. Many contents are shown in textbooks but cannot teach (or reduce teaching hours compared to regulations). Instead, some content is not included in the curriculum but appears in teaching practice to meet these exams. For mathematics, algebraic transformation techniques are complicated beyond the curriculum regulations that appear in teaching practice. Moreover, Vietnamese students want to go to major universities to take extra classes outside of formal school hours.

Since 2002, the Ministry of Education and Training took responsibility for university entrance exams instead of universities to reduce this situation. From 2016 to 2017, the Vietnamese Ministry of Education and Training has changed the form of the mathematics exam, from the constructed-response test to the multiple-choice test.

Multiple-choice questions help eliminate types of tasks that their techniques are lengthy and complicated (beyond the limit of the curriculum) and can refer to more the curriculum. These questions impact teaching practice: teachers do not dare to give up or reduce the meaning of mathematic knowledge. In a way, it enhances the coherence between teaching goals and assessment.
However, this form of examination has also caused some incoherence between the current textbooks (in Vietnam, there are only ones of the Ministry of Education and Training) with student assessment. Many new types of tasks appear instead of task types in the textbook to match the time of answering multiple-choice questions to combat the calculator's use. These types of tasks cause many difficulties for teachers and students.

The case of Vietnam seems to be like many other countries. Therefore, the assessment should be changed consistently with the curriculum's core content, increasing students' equality (does not facilitate students to have extra classes) and cannot rely solely on one exam.

\section{REFERENCES}

[1] A. Bessot, C. Comiti. Some Comparative Studies between French and Vietnamese Curricula, Mathematics Education in Different Cultural Traditions-A Comparative Study of East Asia and the West, Springer, 2006.

[2] Y. Chevallard. La transposition didactique - Du savoir savant au savoir enseigné, La pensée sauvage, 1991.

[3] Y. Chevallard, G. Sensevy. Anthropological Approaches in Mathematics Education. French Perspectives, Encyclopedia of mathematics education, Springer, 2014.

[4] Giao duc Viet Nam, Thi trắc nghiệm khách quan có phải là một cuộc cách mạng trong đánh giá?, Online available from https://giaoduc.net.vn/giao-duc-24h/thi-trac-nghiem-khachquan-co-phai-la-mot-cuoc-cach-mang-trong-danh-gia-post1 71942.gd

[5] Giao duc Viet Nam, Thi trắc nghiệm môn Toán, tranh cãi trái chiều chưa hồi kêt, Online available from https://giaoduc.net.vn/giao-duc-24h/thi-trac-nghiem-mon-to an-tranh-cai-trai-chieu-chua-hoi-ket-post204674.gd

[6] D. Quynh. Calculus 12 (Advanced), Vietnam Education publishing house, 2010.

[7] Ministry of Education and Training. The curriculum of Mathematics, Ha Noi, 2006.

[8] Ministry of Education and Training. The mathematics illustrated test for the 2017 National High School Exam, Ha Noi, 2016.

[9] Ministry of Education and Training. The mock mathematics test for the 2017 National High School Exam, Ha Noi, 2017.

[10] Ministry of Education and Training. The mathematics reference test 2017 National High School Exam, Ha Noi, 2017.

[11] Ministry of Education and Training. The mathematics official tests for the 2017 National High School Exam, Ha Noi, 2017.

[12] Ministry of Education and Training. The school curriculum of Mathematics, Ha Noi, 2018.

[13] M. Niss, "Mathematical standards and curricula under the 
influence of digital affordances - different notions, meanings and roles in different parts of the world,” Digital curricula in school mathematics, Information Age Publishing, 2016, 239-250.

[14] Nguoi Lao Dong, Phản ứng gay gắt về thi trắc nghiệm toán, Online available from https://nld.com.vn/giao-duc-khoa-ho c/phan-ung-gay-gat-ve-thi-trac-nghiem-toan-201609122156 29018.htm

[15] N. T. Nga, T. T. Oanh. Test with redaction and multiple-choice questions: Variables of the types of tasks related to the concept of integration, Ho Chi Minh City University of Education Journal of Science, Vol.14, No.10, 39-50, 2017.

[16] N. T. Nga, T. T. Oanh. Analysis of teaching practice on the concept of integration in the context of the high school national examination held by objective tests, Ho Chi Minh City University of Education Journal of Science, Vol.15, No.10, 120-129, 2018.

[17] Thanh Nien Online, Khẩn thiết đề nghị Phó thủ tướng xem xét lại việc thi trắc nghiệm hoàn toàn môn toán, Online available from https://thanhnien.vn/giao-duc/khan-thiet-denghi-pho-thu-tuong-xem-xet-lai-viec-thi-trac-nghiem-hoantoan-mon-toan-1144420.html

[18] L. T. B. Thien Trung. Notion de limite et décimalisation des nombre réels au lycée, Édition Universitaire Europénnes, 2010.

[19] L. T. B. Thien Trung, V. V. Phat. A study of student's mathematical communication competency through a derivative teaching situation, Ho Chi Minh City University of Education Journal of Science, Vol.16, No.4, 40-52, 2019.

[20] Vietnamnet, Giới toán học không cùng quan điểm về thi trắc nghiệm môn Toán, Online available from https:/vietnamnet.vn/vn/giao-duc/khoa-hoc/gioi-toan-hoc-b at-dong-ve-thi-trac-nghiem-mon-toan-326405.html

[21] Doi song va Phap luat, Thiếu người học Toán và "hiểm họa" từ thi Toán trắc nghiệm, Online available from https://www.doisongphapluat.com/giao-duc/thieu-nguoi-ho c-toan-va-hiem-hoa-tu-thi-toan-trac-nghiem-a340969.html 